\title{
Vitamin E prevents cold wrap restraint stress-induced intestinal fluid transport alterations in rats
}

\author{
SCOTt Burdick BSc, Ningren CUI MD, LONNIE R EMPEY MD, Richard N FEDORAK MD
}

\begin{abstract}
S BURDICK, N CUI, LR EMPEY, RN FEDORAK. Vitamin E prevents cold wrap restraint stress-induced intestinal fluid transport alterations in rats. Can J Gastroenterol 1994;8(7):417-421. Psychological stress may alter gastrointestinal absorptive function by increasing the quantity of intestinal free radicals or by lowering endogenous intestinal free radical scavenging capacity. Vitamin E has been shown to be a potent endogenous antioxidant and free radical scavenger under both physiological and pathological conditions. The purpose of this study was to determine whether cold wrap restraint stress altered in vivo intestinal fluid absorption in rats, and whether vitamin $\mathrm{E}$ administration prior to the induction of cold wrap restraint stress could prevent such changes in intestinal secretion. Jejunal, ileal and colonic fluid and electrolyte transport rates were measured in vivo using an isolated loop technique. Cold wrap restraint stress reduced in vivo fluid absorption in the ileum and colon, but not in the jejunum. Administration of vitamin $\mathrm{E}$ prior to the cold wrap restraint stress procedure completely prevented this alteration of ileal and colonic fluid absorption.
\end{abstract}

Key Words: Absorption, Fluid and electrolyte, Free radical, Intestine, Stress, Transport, Vitamin E

La vitamine E prévient l'altération du transport des liquides dans l'intestin de rats soumis à un stress par enveloppement froid

RÉSUMÉ : Le stress psychologique peut altérer l'absorption gastro-intestinale en augmentant la quantité de radicaux libres ou en abaissant la capacité endogène de l'intestin à les piéger. La vitamine E s'est révélée être un puissant anti-oxydant endogène piégeur des radicaux libres dans des conditions, tant physiologiques que pathologiques. Le but de cette étude était de déterminer si un stress provoqué par un enveloppement froid modifiait in vivo l'absorption liquidienne de l'intestin chez le rat et si l'administration de vitamine $\mathrm{E}$ avant l'induction du stress par enveloppement froid pouvait prévenir de tels changements au niveau de la sécrétion intestinale. Le taux de transport des liquides et des électrolytes au niveau jéjunal, iléal et colique ont été mesurés in vivo à l'aide d'une technique de loupe isolée. Le stress induit par l'enveloppement froid a réduit l'absorption des liquides in vivo au niveau de l'iléon et du côlon, mais non pas au niveau du jéjunum. L'administration de vitamine $\mathrm{E}$ avant l'enveloppement froid a complètement empêché cette altération de l'absorption de liquide au niveau de l'iléon et du côlon.

Division of Gastroenterology, Department of Medicine, University of Alberta, Edmonton, Alberta

Correspondence: Dr Richard N Fedorak, Division of Gastroenterology, University of Alberta, 519 Robert Newton Building, Edmonton, Alberta T6G 2C2. Telephone (403) 492-6841, Fax (403) 492-3744

Received for publication April 21, 1994. Accepted July 21, 1994 $\prod \begin{aligned} & \text { HE EFFECTS OF PSYCHOLOGICAL } \\ & \text { stress on gastrointestinal functions }\end{aligned}$ have been known for more than a century and a half (1). Stress can alter gastric acid secretion, intestinal motility, and fluid and electrolyte absorption rates in nondiseased intestine as well as in the intestine displaying inflammatory changes, irritable bowel syndrome or celiac sprue (2-4). While an endogenous mediator regulating and coordinating gastrointestinal secretory and motor responses following stress has not been identified, recent evidence has shown that stress is capable of upregulating the generation of reactive oxygen metabolites and that these reactive oxygen metabolites have physiological consequences $(5,6)$.

Reactive oxygen metabolites exert a multitude of biological effect in the gastrointestinal tract, ranging from cell death to nontoxic alterations in the intestinal fluid and electrolyte transport, motility and mutagenic activity (7-11). Application of physiological, noncytotoxic concentration of hydrogen peroxide $\left(\mathrm{H}_{2} \mathrm{O}_{2}\right)$, hypochlorous acid $(\mathrm{HOCl})$ or monochloramine $\left(\mathrm{NH}_{2} \mathrm{Cl}\right)$ to the serosal surface of rat colon mounted in Ussing Chambers elicits marked increases in net water and chloride sercetion (11,12). Furthermore, the $\mathrm{H}_{2} \mathrm{O}_{2}$ - and $\mathrm{NH}_{2} \mathrm{Cl}$ mediated increases in chloride secretion are inhibited by atropine, tetradotoxin and piroxicam, suggesting that the cholinergic nervous system and prostaglandins may be important in this response $(11,13)$. Taken to- 


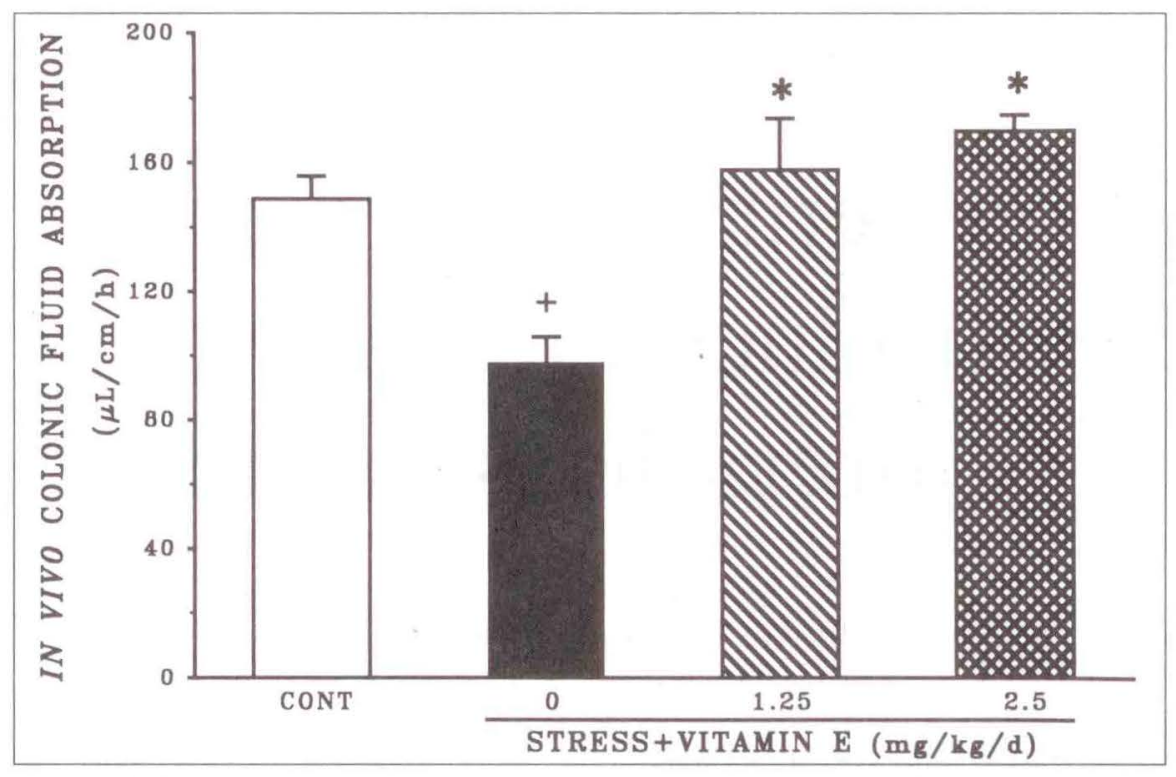

Figure 1) Effect of vitamin $E$ on in vivo colonic fluid absorption in rats with cold wrap restraintinduced stress. Values are mean \pm SEM for $n=6$ rats. ${ }^{+} \mathrm{P}<0.05$ compared with nonvitamin $E$ (sham)-treated nonstressed group. ${ }^{*} P<0.05$ compared with the nonvitamin E-treated cold wrap restraint stressed group

gether, these data suggest that some of the alterations in intestinal fluid and electrolyte transport associated with stress may be mediated by reactive oxygen species.

Reactive oxygen species are continuously produced as metabolic byproducts by virtually all tissues in relatively small amounts. Under basal conditions, oxidant-generating systems in the intestine are compensated for by complex sets of protective mechanisms that prevent or limit oxidative damage. These mechanisms include antioxidant enzymes (superoxide dismutase, catalase and glutathione peroxidase) and nonenzymatic free radical scavengers $(14,15)$. A free radical scavenger represents one type of antioxidant that is defined as any substance that will donate an electron to a free radical, thus inactivating the radical species. Alpha-tocopherol (vitamin E) has recently been identified as one of a number of biologically significant, endogenous, nonenzymatic free radical scavengers (15).

This study investigated whether alterations in functional intestinal fluid and electrolyte absorption occurred as a result of the induction of cold wrap restraint stress in rats and whether the administration of vitamin $E$, perhaps through its free radical scavenging effect, prevented the occurrence of these fluid transport abnormalities.

\section{MATERIALS AND METHODS}

L-alpha-tocopherol (vitamin E), Lot 86F-0370, purity $95 \%$, was purchased from Sigma Chemical Company (Missouri). Alpha-tocopherol standard was purchased from Eastman Organic Chemicals (New York). Xylazine, 20 $\mathrm{mg} / \mathrm{mL}$, was purchased from the Bayvert Division of Chemagro Limited. Ketamine hydrochloride, $100 \mathrm{mg} / \mathrm{mL}$, was purchased from MTC Pharmaceutical. The remainder of the chemicals used were reagent grade and were purchased from Sigma Chemical Co. The $\mathrm{L}$-alpha-tocopherol was diluted with $25 \mathrm{~mL}$ of methyl cellulose to a final concentration of $5 \mu \mathrm{g} / \mu \mathrm{L}$.

Animals: Male Sprague-Dawley rats, 250 to $300 \mathrm{~g}$, were randomly divided into four groups: group 1, nonvitamin $\mathrm{E}$ (sham)-treated nonstressed controls; group 2, nonvitamin E (sham)-treated cold wrap restraint stressed animals; group 3, vitamin E-treated (1.25 $\mathrm{mg} / \mathrm{kg} /$ day) cold wrap restraint stressed animals and; group 4, vitamin E-treated (2.5 $\mathrm{mg} / \mathrm{kg} /$ day) cold wrap restraint stressed animals. All animals were given access to standard rat chow
(Wayne Rodent Blox, Continental Grain Co, Illinois) and water ad libitum. A 12-h light-dark cycled animal care facility was used to hold the animals. Animals were allowed seven days to acclimatize to the environment before the studies began.

Vitamin E administration: Vitamin E (1.25 or $2.5 \mathrm{mg} / \mathrm{kg} /$ day in $1 \%$ methyl cellulose) was given once daily by intraperitoneal injection for seven consecutive days prior to stress administration. The control group received intraperitoneal injections of $1 \%$ methyl cellulose for the same length of time. Cold wrap restraint stress: Cold wrap restraint stress was carried out as previously described (5). Briefly, nonfasting rats were lightly anesthetized with ether, and the forelimbs and shoulders were attached to the thoracic trunk with a harness of paper masking tape. The hind limbs were then taped to the body in similar fashion. The animals were put in the cage in a prone position and kept at $4^{\circ} \mathrm{C}$ for $2 \mathrm{~h}$. While restrained, the animals were completely immobilized and remained in one position without struggling. Care was taken during the restraint stress process to prevent injury and to allow the limbs to rest in a neutral position in order to avoid providing a painful stimulus. These studies were carried out in accordance with the guidelines established by the University of Alberta Animal Health Sciences Committee.

In vivo intestinal fluid transport stud. ies: Immediately following restraint stress the animals were anesthetized with a mixture of ketamine and xylazine ( $2: 1$, volume:volume) and kept warm with a thermostatic heat lamp. In vivo intestinal fluid absorption studies were then performed as previously described (16). The intestinal tract was exposed through a midline incision. An occluding ligature was placed at the cecal ascending junction, and the colonic luminal contents were flushed out the rectum with a warm $154 \mathrm{mM}$ sodium chloride solution instilled via a cannula inserted though an incision just distal to the occluding ligature. Residual saline was emptied by gentle manual ex. pression. A colonic loop approximately $12 \mathrm{~cm}$ long, beginning $2 \mathrm{~cm}$ distal to the 


\begin{tabular}{|c|c|}
\hline Group & $\begin{array}{l}\text { Vitamin E } \\
\text { (mmol/L) }\end{array}$ \\
\hline $\begin{array}{l}\text { Nonvitamin E-treated } \\
\text { nonstressed }\end{array}$ & $10.6 \pm 1.2$ \\
\hline $\begin{array}{l}\text { Nonvitamin E-treated } \\
\text { cold wrap restraint stressed }\end{array}$ & $10.8 \pm 0.9$ \\
\hline $\begin{array}{l}\text { Vitamin E ( } 1.25 \mathrm{mg} / \mathrm{kg} / \mathrm{day}) \text { - } \\
\text { treated cold wrap } \\
\text { restraint stressed }\end{array}$ & $18.1 \pm 0.8^{\circ}$ \\
\hline $\begin{array}{l}\text { Vitamin E ( } 2.5 \mathrm{mg} / \mathrm{kg} / \text { day }) \text { - } \\
\text { treated cold wrap } \\
\text { restraint stressed }\end{array}$ & $22.9 \pm 1.2^{*}$ \\
\hline
\end{tabular}

Values are mean $\pm S E M$ for $n=6$ rats. $" P<0.02$ compared with nonvitamin E-treated animals

fluid absorption was not altered by either cold wrap restraint stress or supplementation with vitamin E.

Serum vitamin E levels: Table 1 shows the serum vitamin E levels for each group. Serum vitamin E levels were significantly elevated, in a dose dependent fashion, in each vitamin E supplemented group.

\section{DISCUSSION}

Under physiological conditions free radicals are continuously being produced. In uncontrolled states, the free radicals are able to induce membrane lipid peroxidation. As a consequence of lipid peroxidation, intestinal membrane functions (including transport processes) are markedly impaired. The lipid hydroperoxides, which are formed during lipid peroxidation, can form clusters which create pores in the membrane through which ions can diffuse into the cells; enzymes are inactivated, membrane fluidity decreases, signal transduction is decreased and cytotoxic aldehydes are formed (18).

In order to prevent or minimize free radical-induced tissue damage, antioxidant enzymes such as superoxide dismutase, catalase and glutathione peroxidase mop up excess free radicals. In addition, antioxidants can prevent the formation of free radicals or interfere with the propagation steps of the lipid peroxidation process.

Vitamin $\mathrm{E}$ is the major lipid-soluble, peroxyl radical-trapping, chain-breaking antioxidant in human blood $(19,20)$. Vitamin E consists of four to- copherols and four tocotrienols which are able to interfere with the propagation steps on the lipid peroxidation process. L-alpha-tocopherol is, in vivo, the most abundant and the most bioactive tocopherol (21). The tocotrienols have an unsaturated side-chain which likely functions to retain the molecule in the membrane, while the tocopherol, with its chroman head-group, is responsible for the majority of the antioxidant activity $(6,22,23)$.

Cold stress has been shown to alter both the production of free radicals and the function of the free radical-trapping defence system (24). In rats exposed to cold stress for short intervals of time, physiological free radical-trapping is reduced as a consequence of diminished superoxide dismutase activity (6). In rats exposed to cold stress for longer intervals of time, the activity of glutathione-S-transferase, a major antioxidant, is decreased in liver and adipose tissue, while glutathione levels are markedly reduced in plasma (24).

Physical and psychological stresses have been shown to alter gastrointestinal physiological function in humans and animals (25-29). Psychological stress experienced during dichotomous listening significantly reduced human jejunal fluid absorption through a function of the cholinergic parasympathetic nervous mechanism (25). In animal studies, restraint-based stress-induced changes in intestinal transit and transport were partially mediated by endogenous central nervous system corticotrophin-releasing factor $(28,29)$. Recently, psychological stress has been shown to reduce intestinal bloodflow in animals (30). Indeed, oxygen free radicals represent a critical factor in the development of gastrointestinal injury after intestinal ischemia and reperfusion have occurred (31).

In the present study, cold wrap restraint stress reduced basal in vivo intestinal fluid absorption in the ileum and colon, but not in the jejunum. This regionalization of beneficial effects by mucosal protective agents in the intestine are similar to those previously described in other experimental models of intestinal injury (16). In addition, divergent effects of stress on the small intestine have been previously described and emphasize the independent regulation that exists in different regions of the gastrointestinal tract (29). The decrease in ileal and colonic absorption in the stressed animals occurred in the absence of gross macroscopic ulceration, and thus likely represents changes at the membrane level; perhaps related to alterations in either the transport carrier or in membrane permeability.

Table 1 shows that cold restraint stress does not alter the vitamin $\mathrm{E}$ content in serum, and previous investigations have confirmed that cold stress does not alter vitamin $E$ levels in the rat small intestine (24). This result suggests that, under the conditions of cold restraint stress, the vitamin $\mathrm{E}$ concentration is maintained at sufficient levels to ensure the integrity of the cellular membrane against the action of basal antioxidant enzymes. Whether a functional disturbance in vitamin $\mathrm{E}$ antioxidant activity exists or whether an elevated level of oxidant activity is present under conditions of restraint stress remains to be determined. Vitamin E administration for seven consecutive days prior to the administration of cold wrap restraint stress resulted in a sig. nificant elevation in serum vitamin $\mathrm{E}$ levels. It is thus possible that this elevated level of vitamin E might have overridden any functional deficit or elevated oxidant activity induced in the stressed rats.

In the present study, intraperito neally administered vitamin $E$ reversed the net intestinal secretory response in the ileum and colon of cold wrap re straint stressed rats to control levels. This effect was seen at doses of both 1.25 and $2.5 \mathrm{mg} / \mathrm{kg} /$ day over seven days The doses are equivalent to those that might be administered to humans un der physiological conditions. It is un likely that the vitamin E directly stimu lated intestinal sodium and chloride absorption because vitamin $\mathrm{E}$ alone administered to control rats did not alter intestinal fluid absorption rates. It i possible that, during the cold wrap re straint stress, the antioxidant defence mechanisms provided by endogenou: levels of normally functioning vitamin 
$\mathrm{E}$ are inadequate to scavenge increased levels of oxygen free radicals or, alternatively, that vitamin $\mathrm{E}$ antioxidant activity is functionally impaired and cannot scavenge baseline levels of oxygen free radicals. Oxygen free radicals in the intestine under these conditions could thus be responsible for the observed alterations in fluid and electrolyte transport. Nevertheless, the exact

\section{REFERENCES}

1. Beaumont W. Experiments and observation on the gastric juices and the physiology of digestion. New York: Cover Publications, 1883.

2. Alp MH, Court JH, Grant AK. Personality pattern and emotional stress in the genesis of gastric ulcer. Gut 1970;11:733.

3. Latimer P, Sarna S, Campbell D, Latimer M, Daniel EE. Colonic motor and myoelectric activity: a comparative study of normal subjects, psychoneurotic patients and patients with IBS. Gastroenterology 1981;88:893-901.

4. Krag E. Irritable bowel syndrome: current concepts and future trends. Scand J Gastroenterol 1985;109(Suppl):107-15.

5. Senay HJ, Levine BT. Synergism between cold and restraint for rapid production of stress ulcers in rats. Proc Soc Exp Biol Med 1967;124:1221-3.

6. Niki E. Antioxidants in relation to lipid peroxidation. Chem Phys Lipids 1987;44:1573-6.

7. Yamada T, Grisham MB. The role of granulocyte-derived oxidants in intestinal mucosal injury. In: Schnappe WJ, Collins SM, eds. Effects of Immune Cells and Inflammation on Smooth Muscle and Enteric Nerves. Boca Raton: CRC Press, 1991:295-303.

8. Grisham MB, von Ritter C, Smith BF, Lamont, J, Granger DN. Interaction between oxygen radicals and gastric mucin. Am J Physiol 1987;253:G93-6.

9. Grisham MB, Gaginella TS, von Ritter C, Tamai H, Be RM, Granger DN. Effects of neutrophil-derived oxidants on intestinal permeability, electrolyte transport, and epithelial cell viability. Inflammation 1990;14:531-42.

10. Weiss SJ. Tissue destruction by neutrophils. N Engl J Med 1989;320:365-76.

11. Tamai H, Kachur JF, Baron DA. Grisham MB, Gaginella TS, Monochloramine, a neutrophil-derived oxidant, stimulates rat colonic mechanism responsible for the stressrelated effects and the protective effects of vitamin $E$ remain to be determined.

In summary, cold wrap restraintinduced stress reduced in vivo fluid absorption in the ileum and colon, but not in the jejunum. Administration of vitamin E prior to the cold wrap restraint process prevented the alteration

secretion. J Pharmacol Exp Ther 1991;257:887-93.

12. Bern MJ, Sturbaum CW, Karayalcin SS, Berschneider HM, Wachsman JT, Powell DW. Immune system control of rat and rabbit colonic electrolyte transport. Role of prostaglandins and enteric nervous system. J Clin Invest 1989;83:1810-30.

13. Tamai H, Gaginella TS, Mush MW, Kachur JF, Chang EB. Monochloramine, a neutrophil-derived oxidant, stimulates secretion and increases cytotoxic $\mathrm{Ca}^{2+}$ in T-84 cultured colonic cells. Gastroenterology 1987;98:557. (Abst)

14. Halliwell B, Gutteridge JMC, eds. Free Radicals in Biology and Medicine, 2nd edn. Oxford: Clarendon Press, 1989.

15. Grisham MB, MacDermott RP, Deitch EA. Oxidant defense mechanisms in the human colon. Inflammation 1990;14:669-80.

16. Empey LR, Fedorak RN. Effect of misoprostol in preventing stressinduced intestinal fluid secretion in rats. Prostaglandins Leukot Essent Fatty Acids 1989;38:43-8.

17. Catignani GL, Bieri JG. Simultaneous determination of retinol and $\alpha$-tocopherol in serum or plasma by liquid chromatography. Clin Chem 1983;29:708-12.

18. Marston A. Chronic intestinal ischemia. Acta Chir Scand 1990;555:237-43.

19. Ingold KU, Webb AC, Witter D, et al. Vitamin E remains the major lipid-soluble, chain-breaking antioxidant in human plasma even in individuals suffering severe vitamin $\mathrm{E}$ deficiency. Arch Biochem Biophys 1987;259:224-5.

20. Burton GW, Joyce A, Ingold KU. Is vitamin $\mathrm{E}$ the only lipid-soluble, chain-breaking antioxidant in human blood plasma and erythrocyte membranes. Arch Biochem Biophys 1983;221:281-90

21. Niki E, Takahashi M, Komuro E. Antioxidant activity of vitamin $\mathrm{E}$ in of fluid absorption rates in both the ileum and colon.

ACKNOWLEDGEMENTS: Dr Fedorak is the recipient of a Clinical Investigatorship from the Alberta Heritage Foundation for Medical Research. This work is supported by grants from the Crohn's and Colitis Foundation of Canada and the Medical Research Council of Canada.

liposomal membranes. Chem Lett 1986:1573-6.

22. Niki E, Kawakami A, Saito M, Yamamoto Y, Tsuchiya J, Kamiya Y. Effect of phytyl side chain of vitamin E on its antioxidant activity. J Biol Chem 1985;260:2191-6.

23. Perly B, Smith ICP, Hughes L, Burton GW, Ingold KU. Estimation of the location of natural $\alpha$-tocopherol in lipid bilayers by ${ }^{13} \mathrm{C}$-NMR spectroscopy. Biochim Biophys Acta 1985;819:131-5.

24. Spasic MB, Saicic ZS, Buzadzic B, Korac B, Blagojevic D, Petrovic V. Effect of long-term exposure to cold on the antioxidant defense system in the rat. Free Radic Biol Med 1993;15:291-9.

25. Barclay GR, Turnberg LA. The effect of physiological stress on salt and water transport in the human jejunum. Gastroenterology 1987;93:91-8.

26. McRae S, Younger $K$, Thompson DG, Wingate DL. Sustained mental stress alters human jejunal motor activity. Gut 1982;23:404-9.

27. Almy TP, Kern F, Tulin M. Alterations in colonic function in man under stress. Gastroenterology 1949;12:425-36.

28. Lenz HJ, Raedler A, Greten H, Vale WW, Rivier JE. Stress-induced gastrointestinal secretory and motor responses in rats are mediated by endogenous corticotrophin-releasing factor. Gastroenterology 1988;95:1510-7.

29. Williams CL, Peterson JM, Villar RG, Burks TF. Corticotrophin-releasing factor directly mediates colonic responses to stress. Am J Physiol 1987;253:G582-6.

30. Guth PH, Leung FW. Physiology of the gastric circulation. In: Johnson LR, ed. Physiology of the Gastrointestinal Tract, vol 2. New York: Raven, 1987:1031-53

31. Granger DN, Rutili G, McCord JM. Superoxide radiclas and feline intestinal ischemia. Gastroenterology 1981;81:22-9. 


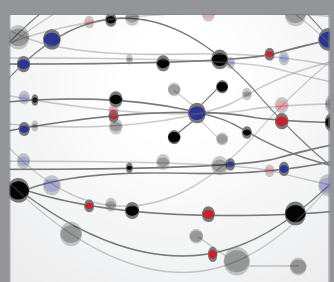

The Scientific World Journal
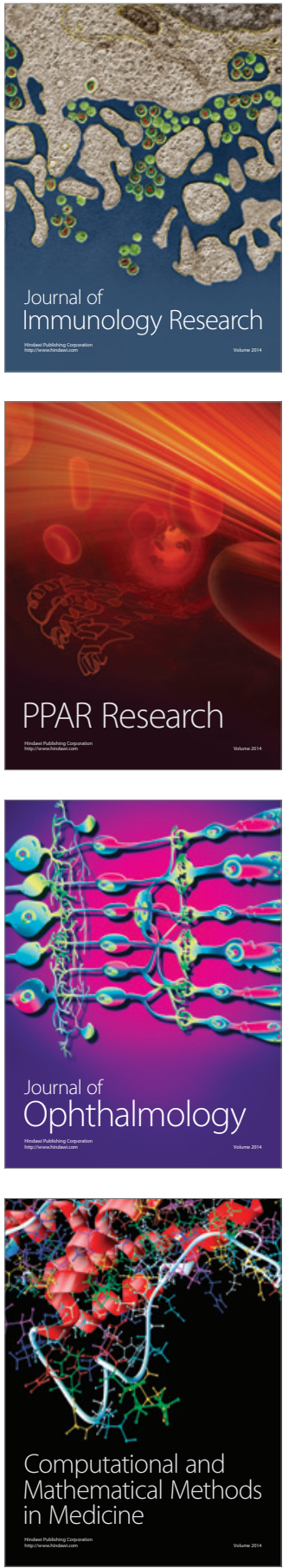

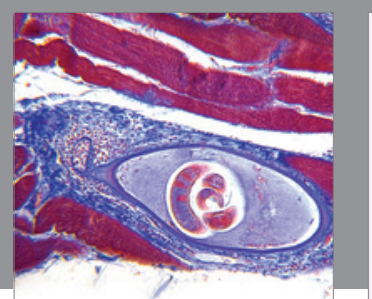

Gastroenterology Research and Practice

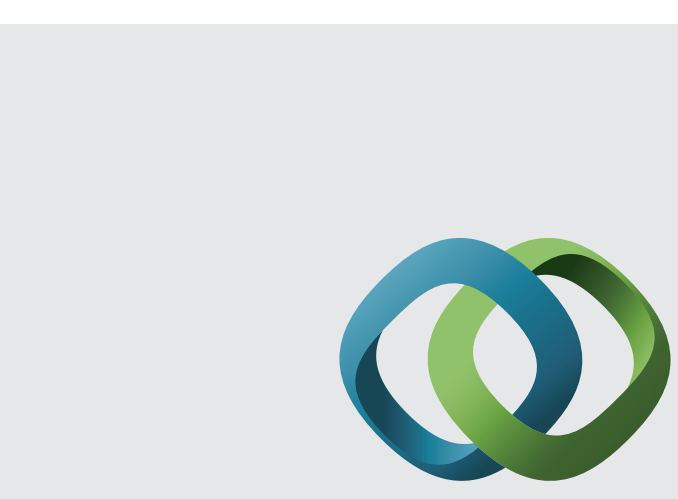

\section{Hindawi}

Submit your manuscripts at

http://www.hindawi.com
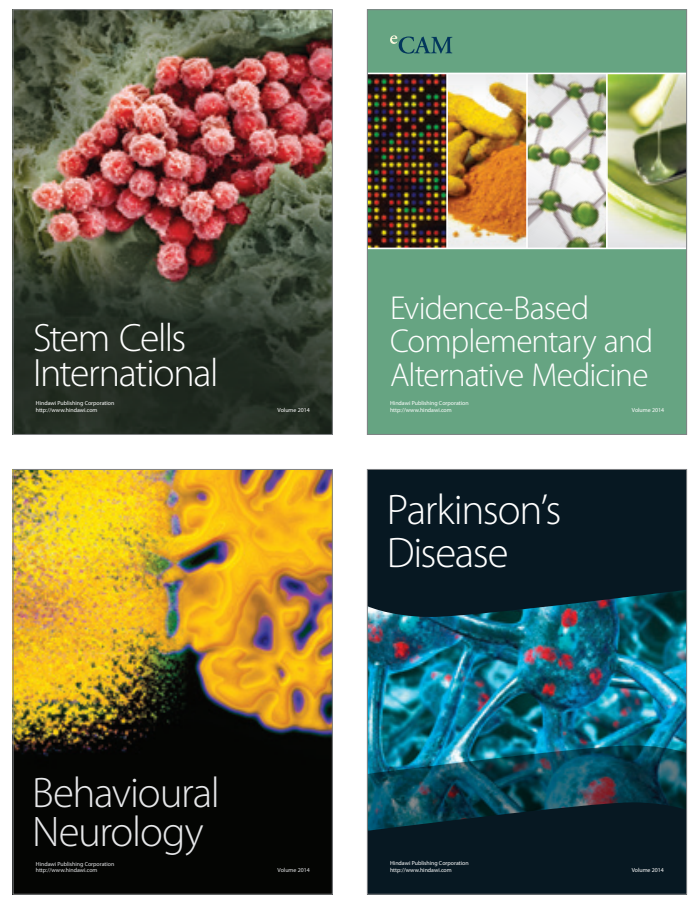
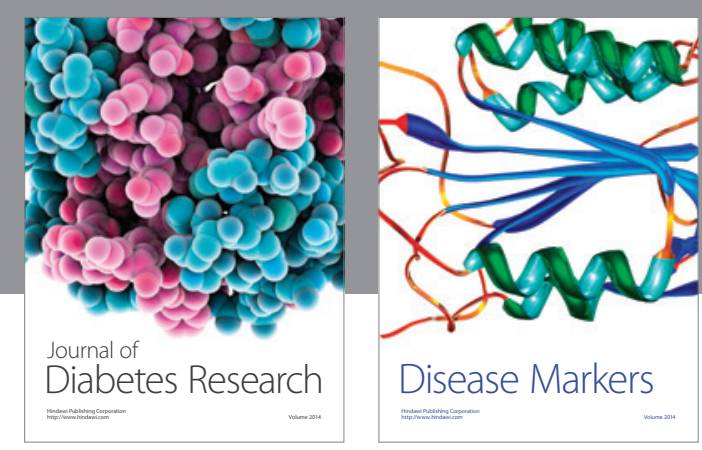

Disease Markers
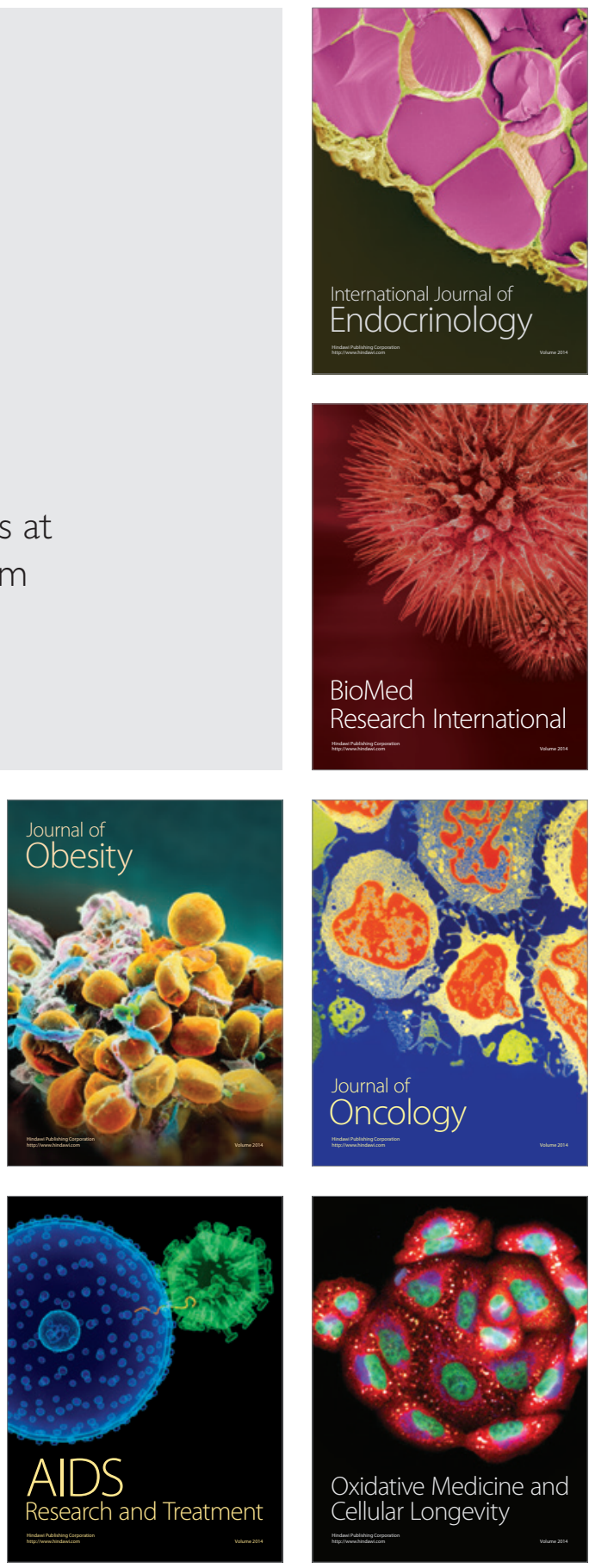